\title{
Epidermoid Cyst - A Clinical Case Report
}

\author{
Kavisha Kapoor Lal', Dhruvendra Lal ${ }^{2}$, Vijay Obed ${ }^{3}$ \\ ${ }^{1}$ Assistant Professor, Department of Periodontics, CDC, Ludhiana, Punjab, India. \\ ${ }^{2}$ Assistant Professor cum CMO, Department of Community Medicine, CMC, Ludhiana, Punjab, India. \\ ${ }^{3}$ Professor, Department of Plastic Surgery, CMC, Ludhiana, Punjab, India. \\ DOI: https://doi.org/10.24321/2349.2880.202112
}

I $\quad \begin{array}{llll}\mathbf{N} & \mathbf{F} & \mathbf{O}\end{array}$

\section{Corresponding Author:}

Dhruvendra Lal, Department of Community

Medicine, CMC, Ludhiana, Punjab, India.

E-mail Id:

drdhruvlal@gmail.com

Orcid Id:

https://orcid.org/0000-0001-6973-9311

How to cite this article:

Lal KK, Lal D, Obed V. Epidermoid Cyst - A

Clinical Case Report. Ind J Youth Adol Health.

2021;8(3):12-14.

Date of Submission: 2021-08-10

Date of Acceptance: 2021-08-26

\section{$\begin{array}{llllllll}\mathbf{A} & \mathbf{B} & \mathbf{S} & \mathbf{T} & \mathbf{R} & \mathbf{A} & \mathbf{C} & \mathbf{T}\end{array}$}

Epidermoid cysts are generally avascular intradermal or subcutaneous masses that can commonly occur anywhere in the body but are specifically seen on the face, neck, and trunk and range from $1-4 \mathrm{~cm}$ in size. These can be asymptomatic. This is a clinical case of a 26-yearold female patient who presented with a large, slow-growing mass in her right gluteal region. Ultrasound was performed as an investigation which revealed a large oval avascular cystic mass in her right gluteal region which later was excised and sent for pathological investigation that revealed an epidermoid cyst measuring $2.8 \times 1.5 \mathrm{~cm}$.

Keywords: Epidermoid Cysts, Sebaceous Cyst, Gluteal Region, Keratin Granules

\section{Introduction}

Epidermoid cysts, also known as cutaneous cysts, are encapsulated sub-epidermal nodules filled with keratin, formed by the entrapment of epidermal cells into the dermis. Epidermoid cysts are commonly lined by squamous epithelium which is stratified. These cysts can exist in any part of the body and are specifically seen on the face, neck, trunk, and back of the body ${ }^{1,2}$ The cysts are mostly benign in nature, however, if left untreated, they may progress slowly over the years and can rarely show malignant transformation. ${ }^{3,4}$ Epidermoid cysts can be seen in a wide range starting from birth to 72 years of age, but are commonly seen in people aged between 15 and 35 years. It has been seen that $7 \%$ of these cysts occur in the head and neck region and in the oral cavity. ${ }^{5}$ The origin of epidermoid cysts can be either congenital or acquired. ${ }^{6}$ They are seen to be associated with an inflammatory response in the hair follicle leading to infundibular epithelium hyperplasia. They can also be seen in Gardner's syndrome in isolated or multifocal form. ${ }^{7}$
At the present time, ultrasound is the primary imaging modality. Ultrasound is often preferred as it has the ability to visualise deeper soft tissue with good spatial resolution. ${ }^{8}$ The scan revealed an oval, well-circumscribed, encapsulated, heteroechoic lesion, measuring $2.8 \times 1.5 \mathrm{~cm}$ in the right gluteal region in the subcutaneous plane. The capsule of the cyst has a general thickness of $2 \mathrm{~mm}$ with no evidence of calcification, necrosis or vascularity noted within the lesion. Clinically, it is very hard to differentiate between benign and malignant soft tissue masses. ${ }^{9}$ Surgical enucleation is the mainstay of surgical management of these cysts.

\section{Case Report}

A 26-year-old female came to Mata Kaushalya Devi Charitable Hospital, a unit of CMC, Hambran, with complaints of abnormal mass in the right gluteal region. The patient informed that the size of the mass had increased significantly over the past year, which made it agonising to sit for an extended period and the mass also hindered her capacity to lie down and pass stool. She denied any previous 
history of trauma and/ or pain in that area. The patient had no history of fever, chills, weight loss, or drainage from that area. There was no history of any swelling on the other body parts. Her medical history was significantly good with no history of hypertension or diabetes or any other co-morbidities. The patient did not have any family history regarding any such complaints. On physical examination, a cystic swelling measuring approximately $3 \mathrm{~cm} \times 2 \mathrm{~cm}$ on the inner aspect of the right hip was observed. Pus points were noted on the surface of the swelling. On palpation, fluctuant swelling, soft to firm in consistency was seen with no discharge and tenderness in the right gluteal region. Differential diagnosis revealed both benign and malignant soft-tissue tumours. Ultrasound examination was done for additional description of the lesion, which showed an oval, well-circumscribed, encapsulated, heteroechoic lesion measuring $2.8 \mathrm{~cm} \times 1.5 \mathrm{~cm}$ in the right gluteal region in the subcutaneous plane. The capsule in this cyst had a thickness of $1.7 \mathrm{~mm}$ with one vessel crossing nearby in the postero-lateral region. There was no evidence of any calcification or necrosis or vascularity within the lesion. The scan gave the impression of an oval, well-circumscribed, encapsulated heteroechoic lesion in the right gluteal region in the subcutaneous plane, which was suggestive of a sebaceous cyst.

Written consent was taken from the patient before the procedure and she was explained in detail regarding the procedure and implications of this surgery. Permission was obtained from the patient regarding the publication of her case and a written declaration was taken. The patient was told that her anonymity shall be maintained at all times. Ethical approval was obtained from the review board and also from the Chief Medical Officer of Mata Kaushalya Devi Charitable Hospital, a unit of CMC, Hambran.

\section{Treatment}

Cysts that are smaller in size usually do not need treatment. Removal of the cyst may be accomplished by simple and complete surgical excision with the cyst wall intact. ${ }^{10}$ The patient, in this case, was positioned in the prone position and the site was cleaned by using betadine solution. A local anaesthetic was injected around the cyst and direct injection of the local anaesthetic into the cyst was avoided. An elliptical incision of small diameter was given with the inclusion of central core of the cyst. The incision was made around the lesion and dissection was started along the plane separating the skin and the capsule. The cyst was excised completely separating it from the underlying fatty layer and was intactly removed (Figures 1 and 2). Homeostasis was achieved. Suturing was done in the layer using 3-0 vicryl for the fatty layer and subcutaneous layer, and 4-0 nylon for the skin (Figure 3). The sutured wound was cleaned with betadine and dressing was done. The patient was started on antibiotics and NSAID for seven days and daily dressings were done till suture removal.

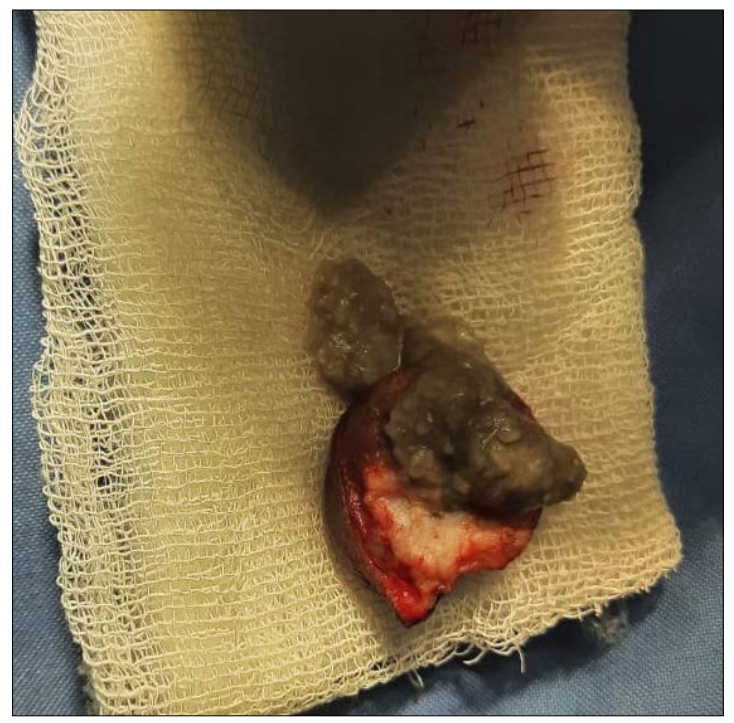

Figure I.Epidermoid Cystic Lesion

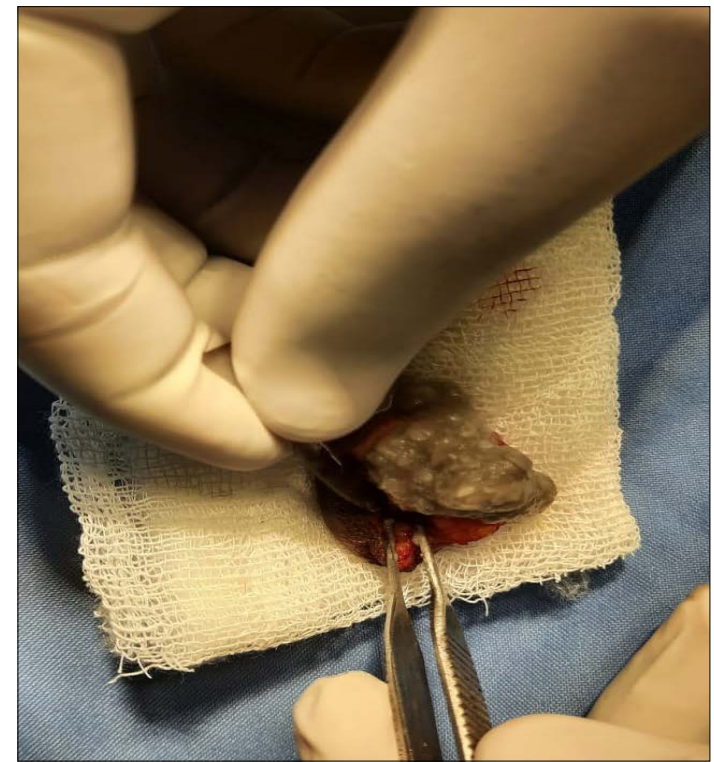

Figure 2.Excised Epidermoid Lesion

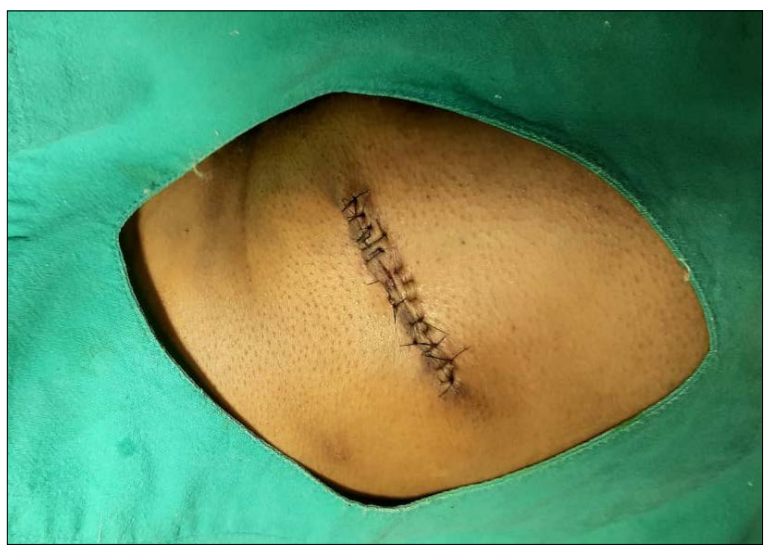

Figure 3.Sutured Site 


\section{Discussion}

A dermoid cyst can be classified as a true dermoid/ epidermoid/ teratoid cyst. An epidermoid cyst is the rarest cyst among all dermoid cysts found commonly in the head and neck region, ${ }^{11}$ although may be located all over the body. $7 \%$ of them are found in the head and neck region and $1.6 \%$ in the oral cavity. Among the oral cysts, there are $0.01 \%$ dermoid and epidermoid cysts. ${ }^{12}$ But in contrast, the cyst in this case study was found in the gluteal region and was of the size of $2.8 \mathrm{~cm} \times 1.5 \mathrm{~cm}$.

A typical epidermal cyst is a usual benign tumour of the skin and is generally a slowly developing mass with size ranging from a few millimetres to a few centimetres. This cyst is most commonly found in younger and middle-aged adults, ${ }^{1,2}$ which is similar to the case in this study where the age of the female is 26 years.

The pathogenesis of epidermoid cyst is controversial, but it is believed that the cyst develops from sequestration and implantation of epidermal cells during the embryonal period and occlusion of pilosebaceous glands followed by iatrogenic or surgical implantation of the epithelium into mesenchyme. ${ }^{11}$

Imaging has been found to play an important role in confirming the diagnosis and classification of these cysts. Ultrasound of the right gluteal region is recommended. ${ }^{13}$ Ultrasound, in this case, revealed an oval, well-circumscribed, encapsulated, heteroechoic lesion in the right gluteal region.

Histopathologically, an epidermoid cyst is lined by keratinized epithelium with areas of pseudo-stratified columnar epithelium cells with cilia and with focal ulcerations. ${ }^{13}$

Needle aspiration or fenestration is generally not recommended as it might lead to infection and pain in large cysts. ${ }^{12}$ Total excision was done in this case and the whole mass was excised and sent for biopsy which revealed a granular layer of keratohyalin granules.

\section{Conclusion}

Epidermoid cysts are generally non-malignant subcutaneous cystic tumours that are uncommonly seen in the gluteal region. They need complete clinical and histopathological examination and close follow up. The cyst might show malignant transformation, so a very close follow up is required in such cases. Prompt diagnosis and eradication of dermoid and epidermoid cysts have critical importance. The use of ultrasound plays an important role in the management of such cases. Complete surgical excision should be the treatment of choice even in the early stages.

\section{Conflict of Interest: None}

\section{References}

1. Houdek MT, Warneke JA, Pollard CM, Lindgren EA,
Taljanovic MS. Giant epidermal cyst of the gluteal region. Radiol Case Rep. 2015 Nov 6;5(4):476. [PubMed] [Google Scholar]

2. Hoang VT, Trinh $\mathrm{CT}$, Nguyen $\mathrm{CH}$, Chansomphou $\mathrm{V}$, Chansomphou V, Tran TT. Overview of epidermoid cyst. Eur J Radiol Open. 2019 Sep5;6:291-301. [PubMed] [Google Scholar]

3. Curtin H, Som P. Head and Neck Imaging. 4th ed. Mosby; 2002;2173-83.

4. Dutta M, Saha J, Biswas G, Chattopadhyay S, Sen I, Sinha R. Epidermoid cysts in head and neck: our experiences, with review of literature. Indian J Otolaryngol Head Neck Surg. 2013;65(Suppl 1):14-21. [PubMed] [Google Scholar]

5. Janarthanam J, Mahadevan S. Epidermoid cyst of submandibular region. J Oral Maxillofac Pathol. 2012;16:435-7. [PubMed] [Google Scholar]

6. Kudoh M, Harada H, Omura K, Ishii Y. Epidermoid cyst arising in the submandibular region. Case Rep Med. 2013;419289. [PubMed] [Google Scholar]

7. Tancredi AR, Ribeiro-Júnior O, Higo CD, Pedron IG, LemosJúnior CA. Epidermoid cyst in the labial commissure region: case report. Clin Pesq Odontol. 2006;2:329-32.

8. Klibanov AL, Hossack JA. Ultrasound in radiology: from anatomic, functional, molecular imaging to drug delivery and image-guided therapy. Invest Radiol. 2015 Sep;50(9):657-70. [PubMed] [Google Scholar]

9. Lin $C Y$, Jwo SC. Squamous cell carcinoma arising in an epidermal inclusion cyst. Chang Gung Med J. 2002;25:279-82. [PubMed] [Google Scholar]

10. Manie MA, Al-Qahtani KH, Al Ammar A, Islam T, Otaibi FN. Epidermoid cyst of the suprasternal region: a rare case report. Braz J Otorhinolaryngol. 2020;86(1):1335. [PubMed] [Google Scholar]

11. Boricha V, Shetty N, Vachhani D, Bangera D, Surabhi V. Just another sebaceous cyst?? - an epidermoid cyst of head \& neck region: a case report. Austin J Dent. 2018;5(4):1114.

12. Kang SG, Kim CH, Cho HK, Park MY, Lee YJ, Cho MK. Two cases of giant epidermal cyst occurring in the neck. Ann Dermatol. 2011;23(Suppl 1):S135-8. [PubMed] [Google Scholar]

13. Mirza S, Fadl S, Napaki S, Abualruz AR. Case report of complicated epidermoid cyst of the floor of the mouth: radiology-histopathology correlation. Qatar Med J. 2014;2014:12-6. [PubMed] [Google Scholar] 